Open Access

\title{
A scaffolding toolkit to foster argumentation and proofs in mathematics: some case studies
}

\author{
Giovannina Albano* ${ }^{*}$ and Umberto Dello lacono
}

\author{
*Correspondence: galbano@unisa.it \\ Dipartimento di Ingegneria \\ dell'Informazione ed Elettrica e \\ Matematica Applicata, Università \\ degli Studi di Salerno, Via Giovanni \\ Paolo II, 132, 84084 Salerno, \\ Fisciano, Italy
}

\begin{abstract}
This paper focus on how language can be seen as an object to be manipulated and how manipulation can act as scaffolding for fostering argumentative competency. To this aim, we have defined a digital toolkit, consisting in virtual "language tiles", made available to the students. The learners can freely articulate their thinking, drag the appropriate tiles in order build sentences for communicating her findings and arguments. The toolkit can also allow automatic assessment of the sentences. We analyse from a theoretical point of view the didactical potential of the toolkit for supporting cognitive process, activating mathematical knowledge and favouring the passage from reasoning, as production of arguments, to expression of arguments, towards construction of formal proof.
\end{abstract}

Keywords: Argumentation, Language, Digital tiles, Mathematics education

\section{Introduction}

It is widely recognized the importance of reasoning and argument as fundamental mathematical capabilities (National Council of Teachers of Mathematics, 2000). This means that the student should be able to explain and provide justification for processes and procedures used as well as to create arguments that support, refute or qualify a mathematical claim. The relation between argumentation and proof is very complex and it has been subject for many studies that can be found in literature (e.g. Arzarello, 2007; Barrier, Mathe, \& Durand-Guerrier, 2009; Boero, 1999; Hanna, 2000; Mariotti, 2006; Stylianides, Bieda, \& Morselli, 2016; Weber, 2014). We assume the idea of continuity between argumentation and proof, as process moving from personal reasoning to the arrangement of deductive chains of arguments (see the construct of "Cognitive unit of theorems" in Boero, 2017). Students' explanations have for sure positive effects on learning, as they foster deep understanding, make their thinking visible, help them in developing ongoing reflections. This also fits the discursive approach to mathematics learning (Sfard, 2001), which considers mathematics learning as a participation to a particular kind of discourse. Also inquiry-based teaching requires the students "explaining, reasoning, arguing and proving" (Artigue \& Blomhøj, 2013, p. 808). Unfortunately, without specific scaffolding students rarely engage in explanations or in argumentation. This is why

(c) The Author(s). 2019 Open Access This article is distributed under the terms of the Creative Commons Attribution 4.0 International License (http://creativecommons.org/licenses/by/4.0/), which permits unrestricted use, distribution, and reproduction in any medium, provided you give appropriate credit to the original author(s) and the source, provide a link to the Creative Commons license, and indicate if changes were made. 
teachers usually support students prompting appropriate questions. Probing questions ask the students to justify and prove their findings and thinking (Sahain \& Kulm, 2008). In particular, conceptual probing questions "invite students to articulate their reasoning or thinking, which requires making the connections explicit” (Hähkiöniemi, 2017, p. 976). Anyway, it is experienced by many teachers, that probing questions are not enough to develop such capability, that it, it cannot be done for grant but it needs specific didactical interventions.

To this aim we present a scaffolding toolkit, named Interactive Semi-open Question (ISQ), consisting in virtual language tiles available to the students in order to construct sentences. It can be used to answer to probing questions as well as to create mathematical proofs. The paper will show a state of art of the use of ISQ in different contexts, analysing, from a theoretical point of view, its educational potential to foster argumentation and proof in mathematics and to automatically assess open-ended questions. The paper will also show some hypotheses of future use of ISQ to some case studies, known in the literature.

\section{Theoretical background}

The emergence of argumentation and proof in students' discourse requires to favour the production of a deductive text according to specific socio-mathematics norms (Mariotti, 2006) and to shared textual conventions that refer to many features of the literate registers of ordinary language, such as: words have precise meanings, syntax is tight, representations are more conventional (Ferrari, 2004). Such text should be the outcome of a complex thinking process, which encompasses formulation of a statement, selection and enchaining of appropriate arguments into a deductive chain, organization of the enchained argument into a proof, approaching formal proof (Boero, 1999). Moving from argumentation as a process (i.e. production of arguments) to argumentation as a product (i.e. expression of arguments) is not taken for granted.

Language is seen as means of objectification, that is an artefact "intentionally used by individuals in social processes of meaning production, in order to achieve a stable form of awareness" (Radford, 2002, p. 14). Dello Iacono \& Lombardi (2015) explored how the manipulation of language tiles is related to the development of logical-deductive abilities in primary school. Pupils extracted information from a suitable text and made it available in form of facts and rule, to be written on magnetic tiles. The authors found that, making language a concrete manipulative object, children were able to answer to some posed questions by constructing simple deductive chains by means of the above magnetic tiles. Linguistic manipulative activities have been also used to investigate the role of language in the development of logical tools (Coppola, Mollo, \& Pacelli, 2011), finding that the manipulation of linguistic symbols fostered the children in solving the tasks.

\section{Linguistic manipulatives in education: literature review}

There are many examples in literature of construction of sentences by manipulating linguistic or symbolic tiles, in various contexts. Many example of linguistic manipulatives can be found in language education. Ryall, Forlines, Shen, and Morris (2004) experimented with a variation of the game Magnetic Poetry, consisting in single magnetic words that can be attached to a metal surface to build a poem or themes. 
Students, working in groups, looked for the tiles and assembled them on the tabletop to create poems. Among the available tiles were also distractors tiles. Adrienne (2010) designed the Sentence Making Game, inspired by the popular game Scrubble, based on the formation of words of complete meaning, that will incorporate one of the letters already on the board using and combining some letters, drawn by lot from a bag. The variation in the Sentence Making Game consists in the fact that the player does not combine letters but words and the goal is not to build words but sentences. The aim of the game is to help students learn English through sentence building by focusing their attention on vocabulary and word order.

On the mathematics side, during the last years virtual manipulatives are very widespread. For instance, the project National Library of Virtual Manipulatives (1999-2006) offer a lot of free virtual app-based manipulatives to foster conceptual understanding of mathematics concepts. Manipulable tiles can be considered manipulators, whose use in mathematics classes has been widely recommended by educators (National Council of Teachers of Mathematics, 1989). A student of any school order is more likely to build a mathematical concept or discover a mathematical relationship through the appropriate use of manipulators, even virtual ones (Durmus \& Karakirik, 2006). Anyway, typically virtual mathematical manipulatives refer to similar concrete manipulatives and does not make use of words.

According to the discursive approach to mathematics learning (Sfard, 2001), it makes sense to have manipulatives dealt with discourses. In this strand, the authors developed a scaffolding toolkit, called Interactive Semi-open Question (ISQ), supporting the expression of arguments, as a deductive text (Albano, Dello Iacono, Mariotti, 2017). Such toolkit is based on the idea of using language as an artefact, that is "not only as a tool for communicating and structuring the world, but above all as an object to manipulate and to reflect on" (Dello Iacono \& Lombardi, 2015, p. 380). The ISQ foresees pieces of language, that consist in groups of words, become virtual objects, called language tiles, made available to the student. The student can freely articulate her thinking, then she can drag the appropriate tiles in order to build sentences for communicating his/her findings and arguments. The three phases of thinking, dragging and communicating are not fixed and sequential but the student moves among them in a continuum back and forth process. The deductive chain can be made visible by using tiles with key words such as because, then, due to, by hypotheses, if, then, and so on. The ISQ toolkit has been already applied in various context of mathematics education, as reported in the following.

\section{State of the arte of the use of ISQ}

In this section we show how the above linguistic toolkit has been used in mathematics learning according to the cited discursive approach.

\section{Using ISQ to foster expression of arguments}

In the frame of moving from reasoning to express reasons by means of sentences in literate registers, the ISQ can supply the students with language tiles that make evident the causal structure of an argumentative sentence. In fact, such a sentence should be 
composed by a main proposition (statement) and a conditional one (argument), linked by a causal conjunction.

Albano, Dello Iacono, Mariotti (2017) shows how to use the ISQ in the context of story problem, analysing the data by means of linguistic tools (Halliday and Hasan, 1976). The students are engaged in facing a problem aimed to focus their attention on the invariance of the angle size corresponding to a circular sector with respect to the radius of the circumference. In the case study, the students are provided with an aerogram, where a circular sector represents $20 \%$ of the total and they are asked to answer to the following question: "How does the angle vary according to the radius variation?". The Fig. 1 shows the language tiles available to each student, which she can drag and juxtapose in order to build her answer.

The given language tiles allow more than one expression of the correct answer, as shown in row 1 and row 2 of Fig. 2. Although the statement and the argument are the same in two sentences, the structure is different as well as the causal conjunctions.

As in the case of close-ended questions, distractors are foreseen in terms of tiles that can be used to construct wrong answers. For instance, this is the case of the tile "is directly proportional" that some students have used to construct the sentence "the angle does not vary because it is directly proportional to the circumference", containing wrong argument (Albano, Dello Iacono, Mariotti, 2017). Comparing the ISQ with a close-ended question, the number of sentences acting as distractors is greater than the usual one, because of various tiles combination. The scaffolding role played by the ISQ is shown in Albano, Dello Iacono, Mariotti (2017), comparing the answer of the student to the same question, posed first as open-ended and then as ISQ. For instance, we report the case of the student S7, which move from a process of reasoning, helped by calculations (Fig. 3), to the product of that reasoning, consisting in a sentence like in Fig. 2.

\section{Using ISQ to go towards formal proofs}

A further application of ISQ concerns the construction of formal proofs, as shown in the following.

When students are engaged in problem solving activities, usually a conjecture arises from their argumentative activity. The reorganization of arguments into a proof cannot be taken

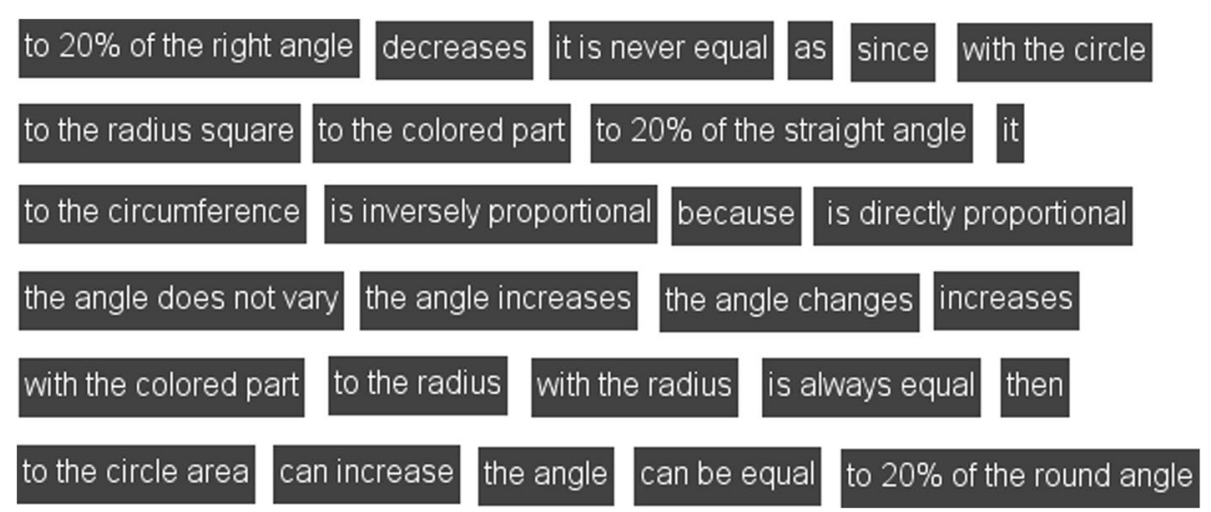

Fig. 1 Language tiles case study in Albano, Dello lacono, Mariotti (2017) 


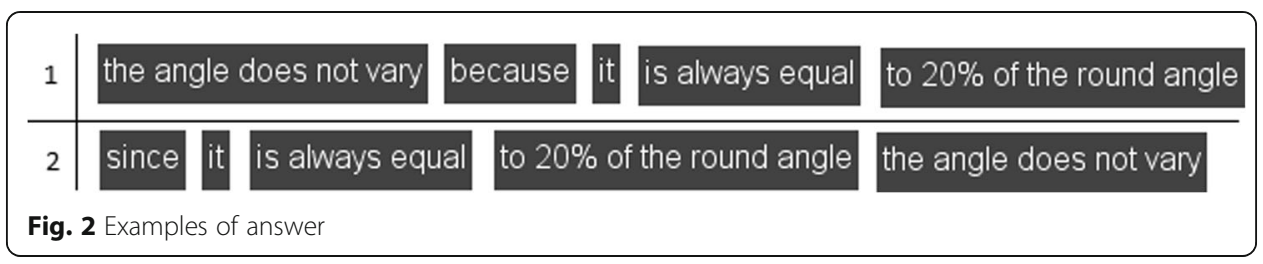

for granted, even if a certain continuity can be devised (Boero, Garuti, \& Mariotti, 1996; Pedemonte, 2007). Some of the difficulties in moving from argumentation to proof concern both the reference system and the deductive structure. In this context, the ISQ has been used in order to implement a kind of a "Bank of Theory", available to the students who are required to formalize some spontaneous justifications given as support of conjectures resulted during dynamic geometry explorations (Albano, Dello Iacono, Mariotti, 2019). The Bank makes explicit the reference system, recalling definitions, properties, theorems at stake (Fig. 4).

Let us see an example of students' answers when moving from free arguments to formal proof by means of ISQ (Table 1).

We note that the use of the linguistic toolkit allowed Erika to focus on some key feature of the figures: in fact, at beginning she refers generally to parallel sides in the parallelogram, without saying which ones, whilst afterwards she specifies that they are "opposite" parallel sides. Also for what the trapezoid concerns, Erika is able to discard inessential information, such as having two oblique sides. Anyway, the use of the Bank of Theory highlights Erika's confusion about the use of the right direction of the definition of the trapezoid.

\section{Use of ISQ in automatic assessment}

Computer-based assessment of open-ended questions is one of the most challenging topic concerning computer-supported learning. As human-based textual analysis needs huge, open-ended questions usually are omitted from quizzes submitted to large numbers of students. Anyway, the drawbacks of using only close-ended questions are well known. One of these is exactly the impossibility of assessing the argumentative competence, as the ability of building an argumentative text (Morgan, 2003). The ISQ can be improved from the computer science point of view equipping each tile with an identification code, consisting for instance in a label defined according to matrix notation (e.g., A2, B5 assuming letters for rows and numbers for columns). So the sentence, built by the student dragging and juxtaposing the tiles, can be rewritten and interpreted in a computer-based environment as an ordered list of identification codes.

Looking at the example in the subsection Using ISQ to foster expression of arguments, the sentence of the row 1 in Fig. 2 corresponds to the following code with respect to the tiles and their matrix labelling in Fig. 1: C1B5B3D4D6.

\begin{tabular}{l|l|l|l}
$\begin{array}{l}\text { The quantity to be represented } \\
\text { is equivalent to } 20 \% .\end{array}$ & $\begin{array}{l}360^{\circ}: 100 \%=\mathrm{x}: 20 \% \\
\mathrm{x}=(360 \times 20): 100=72^{\circ}\end{array}$ & $\begin{array}{l}\text { Although the radius changes, the size } \\
\text { of the angle does not change }\end{array}$ \\
\hline
\end{tabular} Fig. 3 Second example of answer 


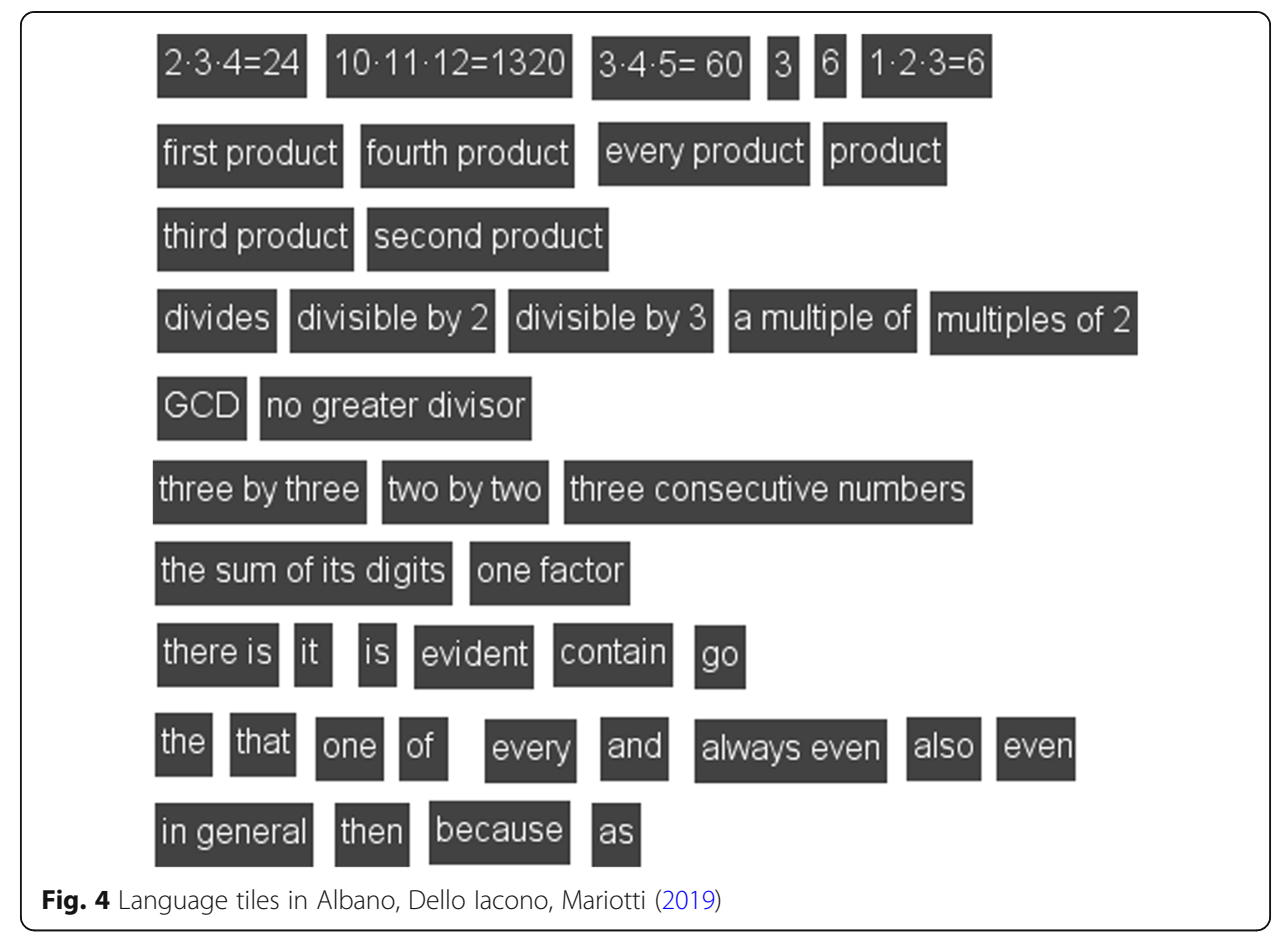

Defining an appropriate algorithm, it is possible to get back automatically from the codes to the student's sentence and then to assess it automatically. It is evident that the feasibility of the automatic assessment of ISQ strongly depends on the numbers of the tiles made available and on the constraints on the number of the tiles that the student should use for building her sentences. In Albano, Dello Iacono, Mariotti (2017), the student should build sentences restricted to five tiles. The automatic assessment can be used both in summative and formative cases. In the latter case, an interesting effect is the possibility to use the outcomes in order to foresee personalized learning paths, according to the detected gaps made evident by the given answer, based on a preliminary analysis of the sentences generated by the tiles.

The automatic assessment requires the integration of the ISQ in a computer-based testing environment, that will have to interpret and assess the answer automatically. A concerned implementation has been done integrating the ISQ in the Lesson module of the platform Moodle, allowing a fine tuning of personalized feedbacks and learning trajectories in a case study (Albano, Dello Iacono, Fiorentino, 2016; Albano \& Dello Iacono 2018a).

Table 1 Example of student's answers by means ISQ

\begin{tabular}{ll}
\hline Erika's free arguments & A B C D is a parallelogram because it has two parallel sides \\
& A E CD is a trapezoid because it has two parallel sides and two \\
& oblique sides. \\
& A B CD is a parallelogram because it has opposite parallel sides \\
Erika's formal proof & A E C D is a trapezoid by Def. 2a \\
\hline
\end{tabular}




\section{Future developments and conclusions}

Starting from the above literature review, theoretical background and the use cases, we are refining and designing the Interactive Semi-open Question (ISQ) as a digital interactive application that consists in a like open-ended question posed to the student and in some virtual objects, being language tiles. The student is expected to build the answer by choosing, dragging and juxtaposing some of the available language tiles. These latter ones allow to construct various sentences, some of them can be acceptable as correct answers to the posed question, some other maybe only partially acceptable, and finally some others not acceptable as they are incorrect answers. The ISQ is not a very open-ended question, but it can be used as a scaffolding to convert the student's thinking into a communicable sentence, under some pre-fixed rules that can be both socio-mathematical and linguistic. In case of argumentation, the ISQ can foster the passage from reasoning as process, that is production of arguments, to expression of arguments. Moreover, being the student in front of a question in style open-ended, she is brought naturally to think about the answer in a free manner. Then, if language tiles to be made available are appropriately chosen, the student will be able to reformulate her own thinking in a sentence which can be built with some of the given tiles.

The application is born in an educational context whose goal was to foster the argumentative competence scaffolding the moving towards the expression of arguments in a literate register (Ferrari, 2004). In such context, framed in an e-learning platform, there is the need of recognizing automatically the answer given by the students, as we were interested in the supporting the construction of answers including causal proposition which makes explicit the reason of the main statement (Albano, Dello Iacono, Mariotti, 2017). This is why open-ended questions are not manageable and, on the other hand, close-ended questions show many educational limits, as they do not allows to focus on the causal nor deductive structure of the sentences at stake. It is worthwhile to note that the ISQ, we implemented by using GeoGebra, and embedded into Moodle platform, can be integrated into any other web environment, supplying it with a new kind of question (Albano \& Dello Iacono, 2018b).

In the near future we plan to pilot testing the tool and analyze the results from an educational perspective to the case studies cited in the previous section. In addition, we want to take further interesting cases known in literature, of which we report below a brief preliminary theoretical analysis.

Let us see the problem (Boero, 2017, p. 3): "Consider all the products of three consecutive natural numbers. What is their GCD? Prove that it is their GCD".

Boero (2017, p. 4) reported the following transcript of a student:

$1 \cdot 2 \cdot 3=62 \cdot 3 \cdot 4=243 \cdot 4 \cdot 5=6010 \cdot 11 \cdot 12=1320$ it is evident that 6 is the GCD of the first three products, because it is the greatest divisor of the first product and a divisor of the other products. Is it a divisor of 1320? ... Yes, 1320 is an even number divisible by 3 because the sum of its digits is a multiple of 3. Then 6 might be the divisor of all the other products too. But why? Probably, by looking at these four products, all the products are even... But why? OK, one factor is always even! Even numbers go two by two, thus among three numbers one number ... one number at least is even, and they may be two, like in the case of 2.3.4. Look at, three is there! And a multiple of three is in the last product! Why? In the case of 2, multiples go two by two ... In the case of 3 , 
numbers go three by three. That is the reason! Now I try to write down the general reasoning: The greatest common divisor is 6 because every product is divisible by 6 because every three consecutive numbers contain one even number (multiple of 2) and one multiple of 3 , because multiples of 2 go two by two, and multiples of 3 go three by three (The teacher writes the following question: Why greatest?) (after a while) Because the first product is divisible by 6 , and no greater divisor is there.

Starting from the above transcript, some tiles can be foreseen for an ISQ shown in Fig. 5:

Note that the language tiles can be grouped together according some educational criteria. For instance, in Fig. 5 the first line contains numerical examples, the fourth and fifth lines refer to the concept of divisibility, the last line contains causal conjunctions. Showing language tiles according some criteria allows to pose the learner's attention on some key points and guide somehow thinking, such as focus on the need of justifying (causal conjunctions) which is not natural, even in front of explicit demand "Justify your answer", or on some mathematical concept involved or needed for proof, such as divisibility criteria. Some of the tiles, such as causal conjunctions or articles, have been made more copies as they can be needed more times, so when the student drags a copy, a new one appears in the same place.

The language tiles in Fig. 5, besides the sentence reported in Boero, allow to build further various correct sentences. For instance, the row 1 and 2 of the Fig. 6 show two alternative possible arguments which can be built. Both of them can continue with the sentence shown in row 3. We note that the tiles available do not contain distractors, but the student should use all the tiles, acting and arranging them as in a puzzle.

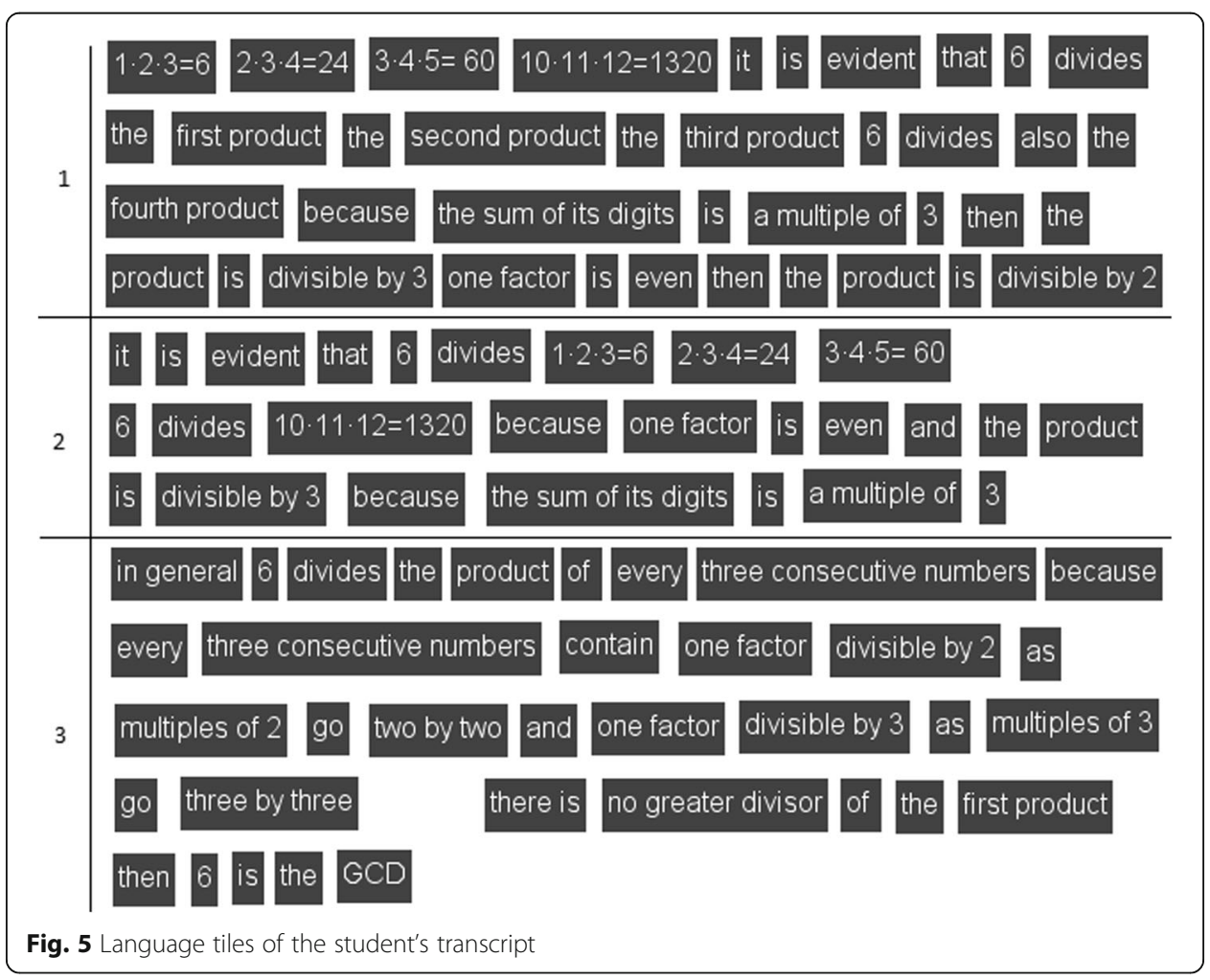




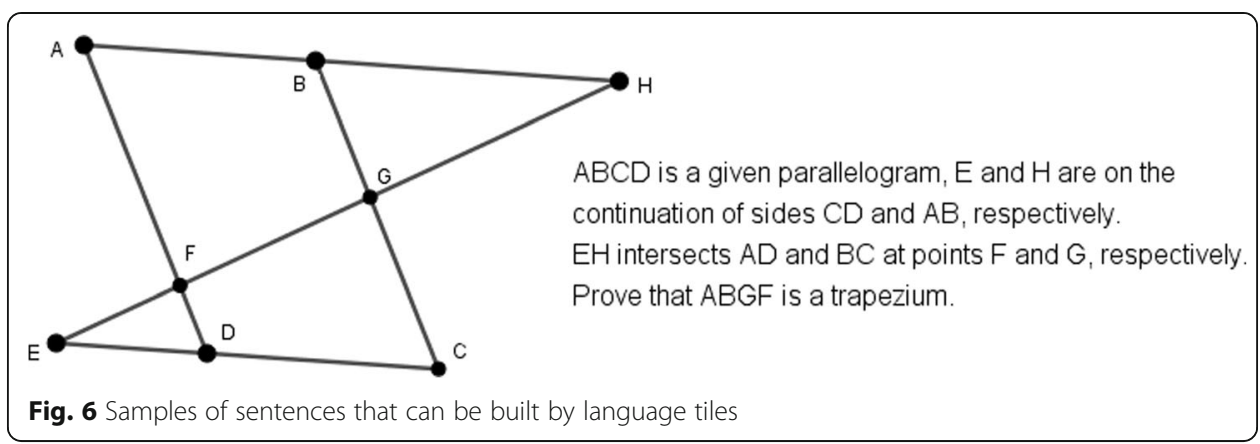

Let us now consider the following problem (Fig. 7) from Haj-Yahya, Hershkowitz, and Dreyfus (2014). The Ramie's proof is given to the students (p. 219): " $A B C D$ is a parallelogram, therefore $A D$ and $B C$ are parallel. $B G$ is part of $B C$ and $A F$ is part of $A D$, hence $A F$ and $B G$ are parallel (parts of parallel sides). We found a pair of opposite parallel sides, therefore ABGF is a trapezium", posing the question: "Did Ramie give a correct and complete proof?"

The outcomes reported in the cited paper show that some students are in trouble with the definition of a parallelogram as limit case of trapezium: "Ramie's proof is correct, he found and proved that there is a pair of parallel sides" (student a13, p. 219), "not correct because it is incomplete, he should prove that the other pair are not parallel, AB is not parallel to FG because they intersect in point H" (student b43, p. 220). In this case the ISQ can be used both for constructing a proof (e.g. Ramie's one) and for detecting such kind of difficulties, planning suitably the tiles, as done in Fig. 8, as they allow to build both the previous students' sentences.

The ISQ toolkit presented in this paper allows to implement a scaffolding methodology for fostering the argumentative competence, with reference both to re-arrange arguments into a deductive chain and to communicate arguments in a verbal-semantic expression. The language tiles, made available by the tool, can be freely dragged and juxtaposed for building sentences, assuming the language as a manipulative artefact. This manipulative feature of the toolkit allows the students to activate thinking and communication processes. In this respect, the use of the toolkit can favour the improvement of mathematical communication, as for what concerns the passage from colloquial registers to literate ones (Ferrari, 2004), and the agreement to socio-mathematics norms

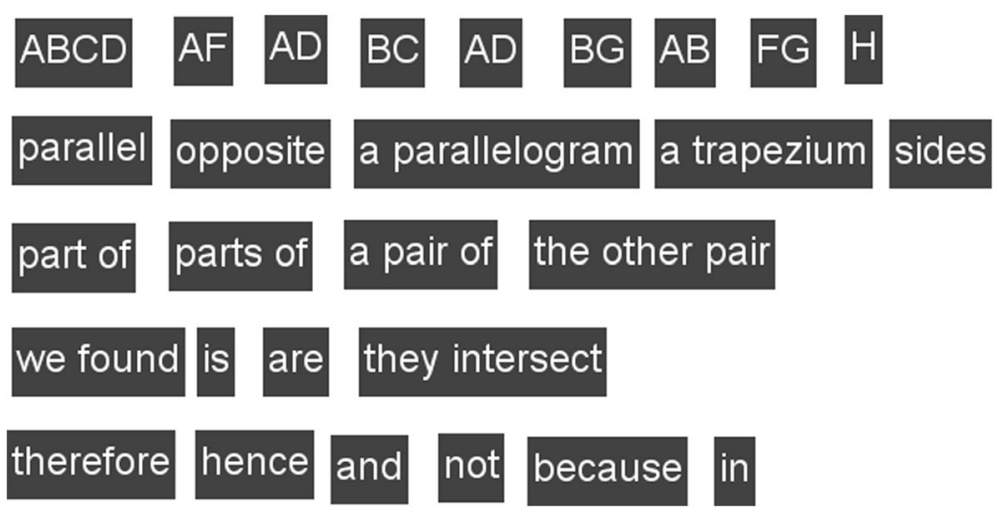

Fig. 7 Geometrical problem in Haj-Yahya et al. (2014) 


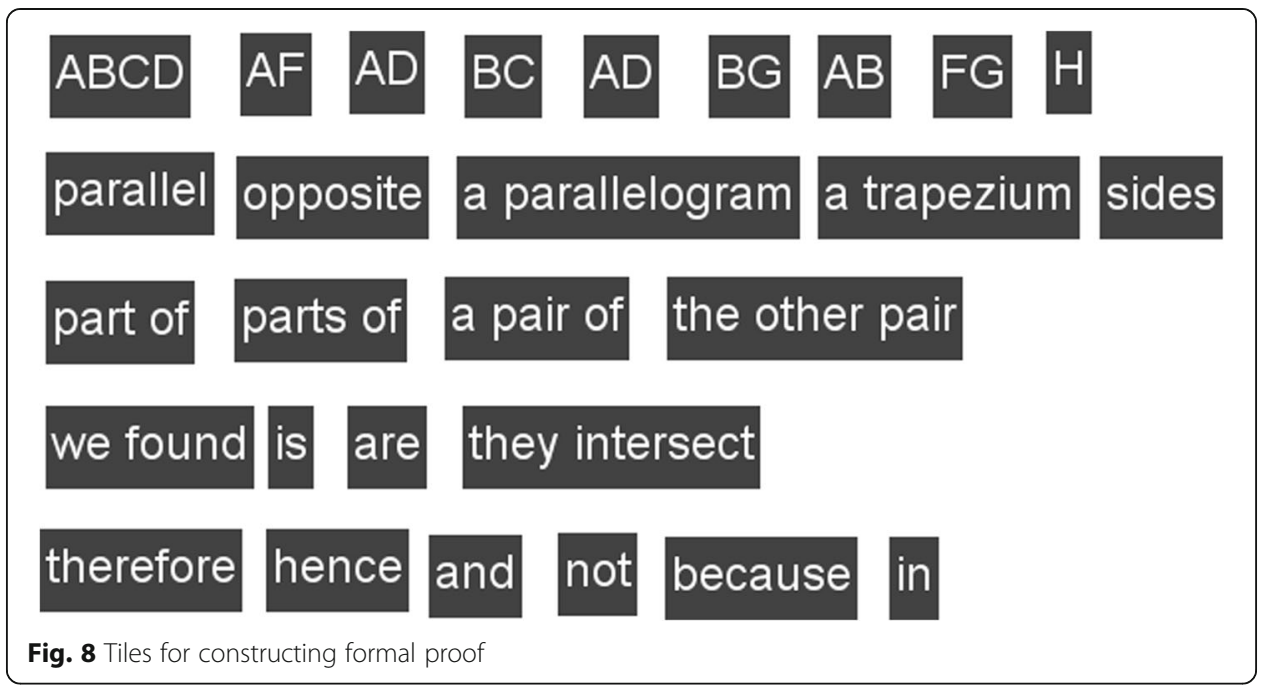

which regulate communication among mathematicians (Mariotti, 2006). Thus it supports the students in a shift from own reasoning to expressing themselves in and about mathematics at a more theoretical and technical precision by means of the use of literate registers. Such improvement in using literate registers impacts on advanced mathematical thinking, in the frame of discursive approach to mathematical learning (Sfard, 2001). We also assume that improving communication means also improving the production of mathematical arguments, as the two things are strictly linked, in a back and forth moving. It is worthwhile to note that some language tiles of the toolkit can recall mathematical knowledge (concepts, properties, theorems). So when the student chooses some tiles, she activates not only a cognitive process concerning the construction of sentence she has in mind but, looking at the "mathematical" tiles, she needs to recover her knowledge and to activate connections. In other words, she is somehow forced to deepen mathematical contents.

The ISQ toolkit also permits to preserve the added value of posing an open-ended question instead of other close-ended questions, so having the possibility of working on argumentative competency and assessing argumentative texts. In fact, the student is left free of answering by means of sentences built by language tiles offered by the tool. The causal structure of the sentence, as well as the conditional structure or whatever else, can be highlighted and fostered by appropriate tiles dedicated to various conjunctions. We observe that, starting from the same set of tiles, the student can build more than one sentences showing correct argumentations or proofs. Different sentences can allow the teacher to be informed on what the student knows and not only on what she lacks, and use this information to steer personalized learning trajectories. From the argumentative point of view, the choice of the tiles to be made available is a crucial for educational effectiveness. The ISQ can be implemented in various typologies, for instance making available: all the tiles which are needed to construct the argumentative sentence, such as a puzzle (see the above first problem); also tiles which can bring to build wrong sentences, such as distractors (see subsection Using ISQ to foster expression of arguments); appropriate tiles to produce a formal proof and also to reason on limit cases concerning mathematical concepts (see the above second problem). Moreover, the ISQ can be used for automatic assessment in computer-based environment. In fact, 
it is possible to label the tiles in order to automatically re-construct the sentence (see subsection Use of ISQ in automatic assessment) and the assess its correctness.

From the educational point of view, the toolkit can be used at every level of school degrees, from primary school to university, choosing appropriate language tiles. The toolkit can be framed into an inquiry-based approach, where students are steered to explore and to conjecture and then they are supported in proving or refuting their findings, also constructing counter-examples.

Anyway, some alerts in using the ISQ methodology can be depicted. The teacher should be careful in choosing the tiles to allow the student to effectively put in words her thinking without restricting her own style of expressing. In fact, increasing the number of tiles greatly increases the number of sentences that can be constructed. As shown in the previous section, the available tiles allow to construct further sentences expressing the same thinking. As drawback, in constructing their sentences, the students can be guided by the choice of words which sound attractive from mathematical point of view, without reflecting on their correctness in the case at stake. This is the case of "direct proportionality", shown in the subsection Using ISQ to foster expression of arguments. Thus, it is important that the teacher makes an a priori analysis of all the sentences that can be constructed by the available tiles, so to be able to manage the educational gaps that can be emerged.

Abbreviation

ISQ: Interactive Semi-open Question

Acknowledgments

Not applicable.

Funding

This research is funded by National Project "Digital Interactive Storytelling in Mathematics: a competence-based social approach", PRIN2015, Prot. 20155NPRA5.

Availability of data and materials

All data generated or analysed during this study are included in this published article or in publications included as references in the reference list.

Authors' contributions

The authors equally contributed to the development of the manuscript and both read and approved the final manuscript. The authors declare that the content of the manuscript has not been published, or submitted for publication elsewhere.

Authors' information

GA is an associate professor at the University of Salerno, Italy, PhD in Pure and Applied Mathematics. Her research interests mainly concern the integration of research in mathematics education and technology. In this regard, she is Principal Investigator of an Italian Research Project of National Interest (PRIN) "Digital Interactive Storytelling in Mathematics: a competence-based social approach". She is authors of many papers about the design of learning activities in e-learning environments as well as the analysis of their impact on students' learning. UDA is PhD in Mathematics, Physics and Applications and researcher in mathematics education at the University of Salerno. His prevailing research interests and his most recent publications concern computer-based collaborative scripts, digital interactive storytelling, logic applied to mathematics education and teaching technologies in mathematics teaching / learning, focused on e-learning platforms and on their integration with other educational technologies.

Competing interests

The authors declare that they have no competing interests.

\section{Publisher's Note}

Springer Nature remains neutral with regard to jurisdictional claims in published maps and institutional affiliations. 
Received: 13 July 2018 Accepted: 4 February 2019

Published online: 28 February 2019

\section{References}

Adrienne, L. G. (2010). Sentence making game: a report on the development of an English learning tool. Bulletin of Shizuoka Sangyo University, 12, 105-126.

Artigue, M., \& Blomhøj, M. (2013). Conceptualizing inquiry-based education in mathematics. ZDM Mathematics Education, 45, 797-810.

Arzarello, F. (2007). The proof in the 20th century: from Hilbert to automatic theorem proving. In P. Boero (Ed.), Theorems in school, (pp. 43-63). Rotterdam: Sense Publishers.

Barrier, T., Mathé, A.-C., \& Durand-Guerrier, V. (2009). Argumentation and Proof: A discussion about Toulmin's and Duval's models. In V. Durand-Guerrier, S. SouryLavergne \& F. Arzarello (Eds.), Proceedings of 6th Congress of the European Society for Research in Mathematics Education (191-200). Lyon, France.

Boero, P. (1999). Argumentation and mathematical proof: A complex, productive, unavoidable relationship in mathematics and mathematics education. In International newsletter on the teaching and learning of mathematical proof (July/August 1999).

Boero, P. (2017). Cognitive unity of theorems, theories and related rationalities. In T. Dooley, \& G. Gueudet (Eds.), Proceedings of the Tenth Congress of the European Society for Research in Mathematics Education (CERME 10, February 1-5, 2017), (pp. 99-106). Dublin: DCU Institute of Education and ERME.

Boero, P., Garuti, R., \& Mariotti, M. (1996). Some dynamic mental processes underlying producing and proving conjectures. In L. Puig, \& A. Gutiérrez (Eds.), Proceedings of the 20 th PME International Conference, (vol. 2, pp. 121-128). Valencia: Universitat de Valencia.

Coppola, C., Mollo, M., \& Pacelli, T. (2011). An experience of social rising of logical tools in a primary school classroom: The role of language. International Journal for Mathematics Teaching and Learning. Retrieved from http://www.cimt.org.uk/ journal/coppola.pdf. Accessed 9 Feb 2019.

Durmus, S., \& Karakirik, E. (2006). Virtual manipulatives in mathematics education: A theoretical framework. Turkish Online Journal of Educational Technology-TOJET, 5(1), 117-123.

Ferrari, P.L. (2004). Mathematical language and advanced mathematics learning.In Johnsen Hoines, M. \& Berit Fugelstad, A. (Eds.), Proceedings of the 28th Conference of PME (pp. 383-390). Bergen, Norway.

Hähkiöniemi, M. (2017). Student teachers' types of probing questions in inquiry-based mathematics teaching with and without GeoGebra. International Journal of Mathematical Education in Science and Technology, 48(7), 973-987.

Haj-Yahya, A., Hershkowitz, R., \& Dreyfus, T. (2014). Investigating students' geometrical proofs through the lens of students' definitions. In Proc. of PME 38, (vol. 3, pp. 217-224). Vancouver: PME.

Halliday, M. A., \& Hasan, R. (1976). Cohesion in English. London: Longman.

Hanna, G. (2000). Proof, explanation and exploration: an overview. Educational Studies in Mathematics, 44, 5-23.

Mariotti, M. A. (2006). Proof and proving in mathematics education. In A. Gutiérrez, \& P. Boero (Eds.), Handbook of research on the psychology of mathematics education, (pp. 173-204). Rotterdam: Sense Publishers.

Morgan, C. (2003). Criteria for authentic assessment of mathematics. Understanding success, failure and inequality. Quadrante, 12(1), $37-51$. National Council of Teachers of Mathematics (1989). Curriculum and evaluation standards for school mathematics. Reston: NCTM.

National Council of Teachers of Mathematics (2000). Principles and standards for school mathematics. Reston: NCTM.

Pedemonte, B. (2007). How can the relationship between argumentation and proof be analysed? Educational Studies in Mathematics, 66(1), 23-41.

Radford, L. (2002). The seen, the spoken and the written: A semiotic approach to the problem of objectification of mathematical knowledge. For the Learning of Mathematics, 22(2), 14-23.

Ryall, K., Forlines, C., Shen, C., \& Morris, M. R. (2004). Exploring the effects of group size and table size on interactions with tabletop shared-display groupware. In Proceedings of the 2004 ACM conference on Computer supported cooperative work, (pp. 284-293). ACM press, Chicago, IL.

Sfard, A. (2001). Learning mathematics as developing a discourse. In Proceedings of 21st Conference of PME-NA, (pp. 23-44). Columbus: Clearing House for Science, mathematics, and Environmental Education.

Stylianides, A. J., Bieda, K. N., \& Morselli, F. (2016). Proof and argumentation in mathematics education research. In A. Gutiérrez, G. C. Leder, \& P. Boero (Eds.), The second handbook of research on the psychology of mathematics education, (pp. 315-351). Rotterdam: Sense Publishers.

Weber, K. (2014). Proof as a cluster concept. In C. Nicol, S. Oesterle, P. Liljedahl, \& D. Allan (Eds.), Proc. of PME 38, (vol. 5, pp. 353-360). Vancouver: PME.

Dello lacono, U., Lombardi, L. (2015). An artefact for deductive activities: a teaching experiment with primary school children. Quaderni di Ricerca in Didattica (Mathematics), n. 25, Supplemento n.2 (Proc. of CIEAEM67, Aosta, Italy: July 20-24 2015), pp. 379-389, ISSN On line: 1592-4424.

Albano, G., Dello lacono, U., Fiorentino, G. (2016). An online Vygotskian learning activity model in mathematics. Journal of eLearning and Knowledge Society (Je-LKS), v.12, n.3, pp. 159-169. ISSN: 1826-6223, e-ISSN:1971-8829 http://www.je-lks.org/ ojs/index.php/Je-LKS_EN/article/view/1169/1017.

Albano, G., Dello lacono, U., Mariotti, M.A. (2017). A computer-based collaboration script to mediate verbal argumentation in mathematics. In Dooley, T. \& Gueudet, G.. (Eds.). Proceedings of the Tenth Congress of the European Society for Research in Mathematics Education (CERME10, February 1 - 5, 2017). Dublin, Ireland: DCU Institute of Education \& ERME.

Albano G., Dello lacono U. (2018a). DIST-M: scripting collaboration for competence-based mathematics learning. In: Silverman J. Hoyos V. (eds). Distance Learning, E-Learning and Blended Learning of Mathematics (pp. 115-131), Cham:Springer, https://doi.org/10.1007/978-3-319-90790-1.

Albano, G., Dello lacono, U. (2018b). GeoGebra in e-learning environments: a possible integration in mathematics and beyond. Journal of Ambient Intelligence and Humanized Computing, 1-13, https://doi.org/10.1007/s12652-018-1111-x.

Albano, G., Dello lacono, U., Mariotti, M.A. (2019). A computer-based environment for argumenting and proving in geometry. Proceedings of the Eleventh Congress of the European Society for Research in Mathematics Education (CERME11, February 6 - 10, 2019). Utrecht, the Netherlands (in press).

Sahain, A., \& Kulm, G. (2008). Sixth grade mathematics teachers' intentions and use of probing, guiding, and factual questions. Journal of mathematics teacher education, 11(3), 221-241. 